\title{
Homologous recombination is unlikely to play a major role in influenza B virus evolution Guan-Zhu Han*†1,2, Xi-Ping Liu ${ }^{\dagger 2}$ and Si-Shen $\mathrm{Li}^{* 1}$
}

Address: ${ }^{1}$ National Key Laboratory of Crop Biology, College of Agronomy, Shandong Agricultural University, Tai'an 271018, China and ${ }^{2}$ College of Life Science, Shandong Normal University, Jinan 250014, China

Email: Guan-Zhu Han* - hanguanzhu@yahoo.com; Xi-Ping Liu - lixiping1988@yahoo.com.cn; Si-Shen Li* - ssli@sdau.edu.cn

* Corresponding authors †Equal contributors

Published: 27 May 2008

Virology Journal 2008, 5:65 doi:10.1186/1743-422X-5-65

This article is available from: http://www.virologyj.com/content/5/I/65

(c) 2008 Han et al; licensee BioMed Central Ltd.

This is an Open Access article distributed under the terms of the Creative Commons Attribution License (http://creativecommons.org/licenses/by/2.0), which permits unrestricted use, distribution, and reproduction in any medium, provided the original work is properly cited.

\begin{abstract}
Influenza B viruses cause a significant amount of morbidity and mortality. The occurrence of homologous recombination in influenza viruses is controversial. To determine the extent of homologous recombination in influenza $B$ viruses, recombination analyses of 2,650 sequences representing all eight segments of the influenza $B$ viruses were carried out. Only four sequences were indentified as putative recombinants, which were verified using phylogenetic methods. However, the mosaics detected here were much likely to represent cases of laboratory-generated artificial recombinants. As in other myxoviruses, it is unlikely that homologous recombination plays a major role in influenza $B$ virus evolution.
\end{abstract}

\section{Background}

Influenza B viruses cause substantial morbidity and mortality in humans. As a member of the Orthomyxoviridae family, influenza B virus possesses a single-stranded and segmented genome of negative sense. Unlike influenza A viruses, no antigenic shift has ever been detected in influenza B viruses. No subtype divisions of surface antigens exist and two lineages, Victoria lineage and Yamagata lineage, have diverged since 1983 as defined by the phylogenetic relationship of the hemagglutinin (HA) gene [1]. All 11 genes of influenza $B$ viruses have diverged into two new lineages prior to 1987 [2,3]. Reassortment occurs frequently among influenza $B$ viruses and likely allows unrestricted lineage mixing [2].

To date, there is also ample evidence that various forms of non-homologous recombination, albeit rarely, occurs in influenza viruses [4-6]. However, the occurrence of homologous recombination in influenza viruses is controversial and far from proven. For influenza A viruses,
Gibbs et al. proposed that homologous recombination had occurred in the HA gene of 1918 Spanish flu virus [7]. However, the apparent recombination event described by Gibbs et al. is much likely to result from a difference in the substitution rate of evolution between HA1 and HA2 [8]. More recently, Boni et al. demonstrate that homologous recombination is very rare or absent in human influenza A viruses through analyzing a data set of 13,852 sequences representing all eight RNA segments and of both major circulating subtypes, H3N2 and H1N1 [9]. Therefore, whether homologous RNA recombination occurs in influenza viruses is one of the key research questions in influenza virus evolution [10].

\section{Results and Discussion}

To access whether homologous RNA recombination plays a role in the evolution of influenza $B$ viruses, we compiled a data set of 2,650 sequences (PB2, 224; PB1, 230; PA, 230; HA, 330; NP, 236; NA, 687; MP, 332; NS, 381) representing all eight RNA segments. The sequences were 
Table I: Influenza B virus strains with significant recombination signal

\begin{tabular}{|c|c|c|c|c|c|c|}
\hline Segment & Recombinant & Accession No. & Putative Parents & 3SEQ p-value & Breakpoint & $\Delta \mathrm{c}-\mathrm{AlC}$ \\
\hline \multirow[t]{2}{*}{ PB2 } & B/Memphis/5/93 & AY58206I & B/Shiga/T30/98 & $4.496 \times 10^{-21}$ & 1665 & 105.592 \\
\hline & & & B/Alaska/03/I992 & & & \\
\hline \multirow[t]{2}{*}{ PB2 } & B/Norway/l/84 & AFI0I984 & B/Guangdong/05/94 & $6.654 \times 10^{-13}$ & 1206 & 78.8114 \\
\hline & & & B/Chile/3162/2002 & & & \\
\hline \multirow[t]{2}{*}{$\mathrm{HA}$} & B/Memphis/5/93 & AFI29902 & B/Houston/B56/I 997 & $8.988 \times 10^{-11}$ & 885 & 56.3597 \\
\hline & & & B/Houston/I/92 & & & \\
\hline \multirow[t]{2}{*}{ NA } & B/Memphis/3/93 & AFI299I5 & B/Alaska/03/l992 & $1.665 \times 10^{-14}$ & 808 & 70.3841 \\
\hline & & & B/Memphis/I0/97 & & & \\
\hline
\end{tabular}

obtained from the Influenza Virus Resource [11] and then aligned using Clustal X [12]. To gain an initial insight into possible recombination events, each of the eight data sets was analyzed respectively using the 3SEQ [13], the Chimaera [14], and the RDP [15] methods, which are available in RDP (Recombination detection program) software. Interestingly, all these three methods implemented got the same results. Only four potential recombinants were primarily identified (Table 1 ). The recombinants were distributed over only three (PB2, NA, and HA) of the eight influenza $B$ virus RNA segments.

Recombination events were further confirmed and the exact breakpoints were identified using GARD (Genetic Algorithm Recombination Detection) online [16,17]. To better evaluate the evidence for these recombination events, the breakpoints identified by GARD were used to divide the alignment into two parts to construct phylogenetic trees respectively. Phylogenetic trees were generated using the Maximum Composite Likelihood (MCL) method for estimating evolutionary distances and neighbor-joining (NJ) method [18] in MEGA4.0 [19]. The phylogenetic trees were tested with bootstrap of 1000 replicates. The occurrence of incongruent phylogenetic trees, the most compelling evolutionary evidence for recombination, was observed for all the four putative recombinants which further confirmed the results of the recombination analyses above. Meanwhile, topological shifts for each of the recombinants have strong bootstrap support (data not shown).

However, large influenza viral genes in the databases may actually represent assembled artifactual contigs from different but homologous gene segments present in a mixed sample to begin with. Such artifactual contigs are also likely to be produced in a mixed sample by template switching during PCR amplification [20] even if only a single primer set is used. Mixture of viruses was present leading to the illusion of a recombination event as a consequence of the sequencing methodology being employed. A plausible explanation for the "recombinants" detected here is contamination by influenza virus derived PCR products, which could combine during PCR amplification to generate apparent, but artifactual recombinants. None of the three putative recombinant viruses were derived by plaque purification. Furthermore, the same laboratory was the source for all four recombinants and the one putative parental strain. As suggested in influenza A virus [9], further work would be needed to conclusively demonstrate homologous recombination in influenza B viruses. Recombinant influenza virus must either be plaque purified or multiple clones must be isolated and sequenced from the same individual or animal host. The presence of both the recombinant and parental genotypes should be found in the sample [21]. Alternatively, homologous recombination could be demonstrated by showing that recombinant sequences form a distinct lineage circulated among multiple identified individuals [22].

\section{Conclusion}

To sum up, our analysis showed that homologous recombination in influenza B viruses was very rare or absent and could not confer a substantial fitness advantage. Therefore, we conclude that homologous recombination is unlikely to play a major role in influenza B virus evolution.

\section{Competing interests}

The authors declare that they have no competing interests.

\section{Authors' contributions}

GZH, SSL designed the study; GZH, XPL carried out the study; GZH, SSL, XPL drafted the manuscript. All authors read and approved the final manuscript.

\section{Acknowledgements}

We thank Dr Maciej Boni for many highly constructive discussions. We also thank Drs Jon McCullers and Takehiko Saito for providing important information on the strains $\mathrm{B} /$ Memphis/5/93 and $\mathrm{B} / \mathrm{Norway} / \mathrm{I} / 84$ respectively.

\section{References}

I. Hay AJ, Gregory V, Douglas AR, Lin YP: The evolution of human influenza viruses. Phil Trans $R$ Soc Lond B Biol Sci 200I, 356: $186 \mid-1870$. 
2. McCullers JA, Saito T, Iverson AR: Multiple genotypes of influenza B virus circulated between 1979 and 2003. J Virol 2004, 78: $12817-28$.

3. Hiromoto Y, Saito T, Lindstrom SE, Li Y, Nerome R, Sugita S, Shinjoh $M$, Nerome K: Phylogenetic analysis of the three polymerase genes (PB I, PB2 and PA) of influenza B virus. J Gen Virol 2000, 8I:929-937.

4. Khatchikian D, Orlich M, Rott R: Increased viral pathogenicity after insertion of a $28 \mathrm{~S}$ ribosomal RNA sequence into the haemagglutinin gene of an influenza virus. Nature 1989, 340:1567.

5. Orlich M, Gottwals H, Rott R: Nonhomologous recombination between the hemagglutinin gene and the nucleoprotein gene of an influenza virus. Virology 1994, 204:462-465.

6. Suarez DL, Senne DA, Banks J, Brown IH, Essen SC, Lee CW, Manvell RJ, Mathieu-Benson C, Moreno V, Pedersen JC, Panigrahy B, Rojas H, Spackman $E$, Alexander DJ: Recombination resulting in virulence shift in avian influenza outbreak, Chile. Emerg Infect Dis 2004, 10:693-699.

7. Gibbs MJ, Armstrong JS, Gibbs AJ: Recombination in the hemagglutinin gene of the 1918 "Spanish flu". Science 2001 293:1842-1845.

8. Worobey M, Rambaut A, Pybus OG, Robertson DL: Questioning the evidence for genetic recombination in the 1918 "Spanish flu" virus. Science 2002, 296:2II.

9. Boni MF, Zhou Y, Taubenberger JK, Holmes EC: Homologous Recombination is Very Rare or Absent in Human Influenza A Virus. J Virol 2008, 82:4807-48II.

10. Nelson MI, Holmes EC: The evolution of epidemic influenza. Nat Rev Genet 2007, 8:196-205.

II. The Influenza Virus Resource [http://www.ncbi.nlm.nih.gov/ genomes/FLU/Database/select.cgi]

12. Thompson JD, Gibson TJ, Plewniak F, Jeanmougin F, Higgins DG: The CLUSTAL $X$ windows interface: flexible strategies for multiple sequence alignment aided by quality analysis tools. Nucl Acids Res 1997, 25:4876-4882.

13. Boni MF, Posada D, Feldman MW: An exact nonparametric method for inferring mosaic structure in sequence triplets. Genetics 2007, 176:1035-1047.

14. Posada D, Crandall KA: Evaluation of methods for detecting recombination from DNA sequences: Computer simulations. Proc Natl Acad Sci 200 I, 98: I 3757-I 3762.

15. Martin DP, Williamson C, Posada D: RDP2: recombination detection and analysis from sequence alignments. Bioinformatics 2005, 21:260-262

16. GARD (Genetic Algorithm Recombination Detection) [http://www.datamonkey.org/GARD/]

17. Kosakovsky Pond SL, Posada D, Gravenor MB, Woelk CH, Frost SD Automated phylogenetic detection of recombination using a genetic algorithm. Mol Biol Evol 2006, 23:|89|-190|.

18. Saitou N, Nei M: The neighbor-joining method: a new method for reconstructing phylogenetic trees. Mol Biol Evol 1987, 4:406-425.

19. Tamura K, Dudley J, Nei M, Kumar S: MEGA4 Molecular Evolutionary Genetics Analysis (MEGA) Software Version 4.0. Mol Biol Evol 2007, 24:1596-1599.

20. Odelberg SJ, Weiss RB, Hata A, White R: Template-switching during DNA synthesis by Thermus aquaticus DNA polymerase I. Nucl Acids Res 1995, 23:2049-2057.

21. Aaskov J, Buzacott K, Field E, Lowry K, Berlioz-Arthaud A, Holmes EC: Multiple recombinant dengue type I viruses in an isolate from a dengue patient. J Gen Virol 2007, 88:3334-3340.

22. Wittmann TJ, Biek R, Hassanin $A$, Rouquet $P$, Reed $P$, Yaba $P$, Pourrut $X$, Real LA, Gonzalez JP, Leroy EM: Isolates of Zaire ebolavirus from wild apes reveal genetic lineage of recombinants. Proc Natl Acad Sci USA 2007, 104:17123-17127.
Publish with Bio Med Central and every scientist can read your work free of charge

"BioMed Central will be the most significant development for disseminating the results of biomedical research in our lifetime. "

Sir Paul Nurse, Cancer Research UK

Your research papers will be:

- available free of charge to the entire biomedical community

- peer reviewed and published immediately upon acceptance

- cited in PubMed and archived on PubMed Central

- yours - you keep the copyright
BioMedcentral 